\section{The Imaginative Space of Narrative}

Tracey Walker Moir-McClean

University of Tennessee at Knoxville
Narrative imagination creates a space of learning where contemporary and historic knowledge of designed place merge. This paper discusses how an instructor's curation and narration of archival material can provoke design-students to imagine narratives and activeIy visualize processes humans use to construct, inhabit and adjust comfort in place. The concept of narrative imagination presented in this paper is informed by traditional narrative as Marie-Laure Ryan defines it her 2005 article, Narrative and the Split Condition of Digital Textuality: (The traditionalist school) "conceives narrative as an invariant core of meaning, a core that distinguishes narrative from other types of discourse, and gives it a trans-cultural, trans-historical, and trans-medial identity." ${ }^{1}$ The work of Gerard Genette, LeviStrauss, Roland Barthes, Jacques Derrida, Monica Fludernik, John Fiske, James Phelan, Henry Jenkins and others is also influential. ${ }^{2}$

First, to establish vocabulary for this discussion. It is important to clearly distinguish between story and narrative. Story or histoire in French is the abstracted chronology of events, actions and influents in a place. Narrative is the discourse used by a narrator/designer to deliver the story to an audience. Narrators deliver narratives. Narratees receive and interpret narratives. Roland Barthes term 'scriptor' is used to refer to the author of a narrative, since the narrator-narratee interactions of imaginative narratives are more similar to the participatory or emergent scripted narratives of games, cinema, theater, or politics than to traditional literary narratives. ${ }^{3}$ Like, game, cinema, and theater scripts design-based narratives embed multiple interpretative-options. This encourages narratee-players to assemble custom combinations of narrative lines, events, character attributes and actions. Thus, each customized replay of a participatory or emergent design-narrative script exposes different aspects of both the narrative and the place-worlds co-created by narrators and narratee-players. ${ }^{4}$

Several distinctions between games, literary-works and designed place are also relevant: In games or literary-works, the narrative is the end product, and the story-world serves as background and backdrop. In design-process the place-setting for the story-world is the primary product, and imagination of narrative and the histoire of experiences within the story-world are tools to help a designer imagine, configure, and communicate the experience, and performance of place. Fixity of product and completion are other points of contrast. A finished literary or game design project remains a relatively stable product of the scriptor's vision unless hacked. Whereas, after design-products (places) are completed and constructed, a succession of users interpret, envision and revise places to suit their own visions and needs. Thus design-narrative scripts are inherently participatory and emergent. Places and place-narratives are also perpetually incomplete. Completion of the design-product merely sets the stage for new cycles of design driven by a succession of project occupants.

In narrative-based design studios, students assume the roles of both narratee and narrator. As narratees, they receive, perceive, analyze, interpret and critique an instructional narrative. In response to studio prompts and assignments, students design and narrate custom story-worlds that share some (but not all) aspects of the studio 


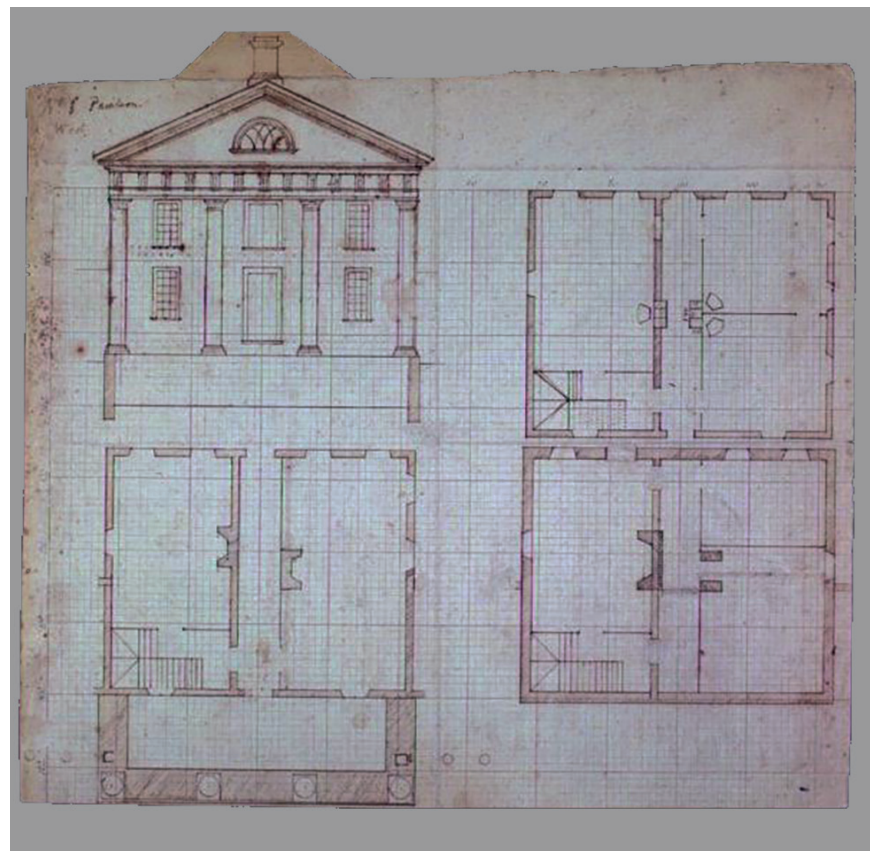

Figure 1. A typical example of Jefferson's sketches for the Pavilions. "No. 1 Pavilion West." University of Virginia, Thomas Jefferson, undated. (circa 1818). (http://www2.iath.virginia.edu/wilson/drawings/images/large/N355.jpg access date $2 / 2 / 2017$ )

story-world. Ideally during design students also develop an ability to consider projects in progress from both the narrator's abstract overview and a narratee's empathetic participation in character experiences within the design world.

Temporal order is another key variable in design-based narrative imagination. While structural or post-structural narratives are both effective tools to employ during imaginative visualization of place, post-structural narrative strategies common to cinema and performance arts encourage imaginative movement across time by disrupting the narratee's position in time. Examples of post-structural strategies that unbalance a narratee's critical position in time, events and place include:

- multiple or alternate reality lines,

- interwoven narratives and temporal periods,

- flashbacks and forwards,

- strategic shifts between character perspectives,

objective and subjective narrative voices,

- as well as variation in social, cultural and ethical frames. ${ }^{5}$

Frequent temporal dislocations within the histoire also encourages design students to adopt and compare a range of value-based perspectives that reflect the agendas and power of different participants within past, contemporary, and future cultural value systems. This suspended unbalance also creates a fluid state of mind ideal for trans-cultural, trans-historical, and trans-medial imagination, critique, synthesis and inter-edits of historic and contemporary design narratives, precedents and products. Literary narratives such as Vonnegut's Slaughterhouse Five, Pynchon's Gravity's Rainbow, and Samuel R. Delany's Dhalgren are fully elaborated examples of the temporal fluidity post-structural narrative structures can add to story-worlds. ${ }^{6}$

The title of the narrative that serves as an example for this paper "Jefferson's Sketchbook" reflects the prime drivers of its histoire and narrative - Jefferson, and his culture, his world-view, his personal working sketches, his passion for and investment in social, cultural and physical evolution of the Lawn at UVa. Full of erasures, changes, rips and stains, scaled only by the graph lines of the paper, Jefferson's sketches are as imperfect and engaging as the man himself --and full gaps into which expository lessons and a participant's imaginative speculation will comfortably fit. (Figure 1)

The Jefferson's sketchbook narrative is scripted for a second-year studio (Architectural Design II). Thus, thematic content is driven by second-year curriculum topics: design order, movement, structure and scale, functional performance as related to passive comfort strategies, socio-culture influents on habitation, and synthetic understanding of the life and performances of campus space. ${ }^{7}$ During the course, students visit select campuses and urban spaces that express curricular themes including Jefferson's Lawn at University of Virginia. Thus, this instructional narrative also juxtaposes the imagined with the actual place and experience. The histoire for the studio narrative covers approximately 200-years from 1817-2018, and addresses the design, construction and subsequent social-cultural and physical change in Lawn Jefferson's Academical Village on The Lawn. The instructional narrative is structured as six studies related to curricular themes and three design exercises. This paper utilizes the instructional narrative for the six studies as an example.

\section{THE SIX STUDIES}

The six studies assigned to students expose and explore phenomenal experience and design influents, structure the oral delivery of the instructional narrative, and guide selection of historic and contemporary readings, images distributed (or hinted at) during the delivery of the full instructional narrative. Table 1 illustrates characters in the instructional narrative used to prompt students to visualize performative flows in each study.

Key event-moments in instructional narrative for the studies include: Jefferson's first conception of an academical village and the letter he wrote to "To the Trustees of the Lottery for East Tennessee College" describing it. ${ }^{8}$ Jefferson studying Palladian geometry. Jefferson sketching preliminary designs for pavilions and arcades on gridded paper (1814-1823).9 Jefferson and his master-craftsmen guiding the various processes and stages of construction on The Lawn (1814-1823). ${ }^{10}$ The year that professors move into the pavilions, students into the rooms, and slaves into the basements or quarters down the hill (1825). ${ }^{11}$ The everyday cycle of teaching, cooking and living in hot humid summers, torrential spring rains, deep red mud, dark nights and bitter cold winter wind. (1825, 2019). Smoldering fires, iron cookpots and basement doors shut tight to keep the heat and smoke of cooking out of the upper levels (1825).

The studies end in a contemporary midnight moment that 


\begin{tabular}{|c|c|c|c|}
\hline influen & title of study & performative flow & characters \\
\hline 1st STUDY HEAT & $\begin{array}{l}\text { THE HEARTH } \\
\text { in the Pavilion }\end{array}$ & Flow Heat and Smoke & master, student. slave, wife. \\
\hline 2nd STUDY THICK & $\begin{array}{l}\text { LANTERN of BRICK } \\
\text { HEARTH-LIGHT } \\
\text { in the Pavilion }\end{array}$ & Flow Hearth Light & $\begin{array}{l}\text { Benjamin Franklin. } \\
\text { Aime Armand. } \\
\text { master, student. slave, wife. } \\
\text { designer. }\end{array}$ \\
\hline 3rd STUDY COOL & $\begin{array}{l}\text { COOLNESS of BREEZE } \\
\text { in the Pavilion, on the Lawn }\end{array}$ & Flow Breeze & master, student. slave, wife. \\
\hline 4th STUDY OCCUPANTS & $\begin{array}{l}\text { UPSTAIRS/ DOWNSTAIRS } \\
\text { in the Pavilion, on the Lawn }\end{array}$ & Flow Served and Servant & master, student. slave, wife. \\
\hline $\begin{aligned} & \text { 5th STUDY DAY } \text { LIGHT } \\
& \text { LIG }\end{aligned}$ & $\begin{array}{l}\text { LANTERN of BRICK } \\
\text { DAY-LIGHT } \\
\text { in the Pavilion }\end{array}$ & Flow Interior Exterior Shadows & $\begin{array}{l}\text { master, student. slave, wife. } \\
\text { designer. }\end{array}$ \\
\hline $\begin{aligned} \text { 5th STUDY ATMOSPHERIC } \\
\text { LIGHT }\end{aligned}$ & $\begin{array}{l}\text { ATMOSPHERIC LIGHT } \\
\text { in the Pavilion, on the Lawn }\end{array}$ & $\begin{array}{l}\text { Flow The COLOR of Daylight } \\
\text { Flow The COLOR of Hearth light }\end{array}$ & master, student. designer. \\
\hline 6th STUDY ORDER & $\begin{array}{l}\text { A GRAMMAR of PROPORTION } \\
\text { \& MEASURE } \\
\text { in the Pavilion, on the Lawn }\end{array}$ & Re ection on Form \& Flow & $\begin{array}{l}\text { Thomas Jefferson, } \\
\text { Andrea Palladio. } \\
\text { Mitchell G. Stiny. } \\
\text { student. designer. }\end{array}$ \\
\hline
\end{tabular}

Table 1. The Six Studies (course assignment, Moir-McClean 2017)

transitions to the design investigation when a genderless faculty member emails the class from Lagos (with appropriate time zone displacement) asking for a narrative design response to the studies. As the design-program phase of instructional narrative begins a group of avatar-students meet their visiting instructor for a seminar class scheduled to meet sometimes in web-space and sometimes physically on the Lawn. Eventually, the actual class travels to UVa. where they experience a doppelganger moment when students from the course meet in the same setting as the imaginary students of 1825 and 2019. Table 2 summarizes the timeline of key events in the studio narrative.

\section{PREPARATION FOR A NARRATIVE BASED STUDIO}

In narrative based studios, the course critic serves as instructor, critic, scriptor, and instructional narrator. Preparation for a narrative-based studio involves typical studio course design practices like identification of curricular goals, conceptual themes and issues, precedent resources, program, location and context influents. In addition to typical elements, a narrative studio requires preparation of a preliminary histoire and narrative line(s) and curation of content to support the narrative. For a narrative studio, content is organized into resource decks. Resource decks are essentially a repository of latent histoire and expose from which the instructional narrator selects -much like an oral narrator pulls narrative elements from memory into his or her current narrative. Resource decks are organized as topical folders on the instructor's cloud/computer drives. Each folder contains a curated set of primary and secondary source texts, archival and graphic documents, images, .mov clips, slide sets, bibliographies of online links, etc. Organized in this way, resources can be quickly flipped through and pulled into the written and oral narrative flow of the studio. Not all material in the resource decks is visible to students or used during the course of the studio. Material may be distributed to individual course members or to the class as a whole. Students may also be shown a sample fragment (a teaser) and the source link to digital archives where the material was sourced as a means to encourage independent exploration. ${ }^{12}$

Employment of resource decks, and delivery of instructional narrative are points where 'the hunch that drives the teaching or research of an educator shapes' this instructional practice. As design instructors know, each academic classyear expresses a distinct energy, tempo, favored issues and concerns. And that the concerns of a class-year are influenced by broader disciplinary dialogue and the interactive chemistry of its constituent members, including faculty assigned to teach on the year-team. In oral traditions, narrators often re-script a histoire during the flow of narrative delivery, adjust content, add emphasis or repetitions to issues, moments and characters that engage a particular audience or that the narrator wishes to reinforce for his/her own purposes. During delivery of the instructional narrative, an educator needs to do the same --letting an intuitive feel for student receptivity and a storyteller's hunch guide the narrative exposé, direction and depth of exploration given to each content study in a studio. An engaging narrator leaves strategic gaps, small 


\section{Table 2. TIMELINE of KEY EVENTS}

1779 Thomas Jefferson introduces "Bill for the More general Diffusion of Knowledge" to the Virginia General Assembly, proposing state education system.

1780 Argand lamp patented by Aimé Argand. (Saltzman, 1999)

1784 Jefferson encounters the lamp in Paris and describes it in a letter to James Madison. (Jefferson, Thomas. 1953)

1810 Thomas Jefferson writes letter describing the Academical Village "To the Trustees of the Lottery for East Tennessee College" describing the Academical Village. (Jefferson, Thomas. 2005) to the Virginia General Assembly, proposing state education system.

1814-1823 Thomas Jefferson corresponds with other architects and draws plans for the University's Academical Village.

1817 Cornerstone laid for Central College building ultimateIy to become Pavilion VII of the University of Virginia. Central College Board of Visitors, including Jefferson, Madison, and Monroe, approve land west of Charlottesville.

1825 First classes meet at University of Virginia, with teaching more than 100 students by year's end. Jefferson Debating and Literary Society founded. Rowdy students disrupt Lawn life, resulting in expulsion of three, including Jefferson's own great-grand-nephew.

1920 Women admitted to the University of Virginia as graduate and professional students.

1950 Gregory H. Swanson, first African-American student at the University, enters Law School.

Table 2. Timeline of Key Events based on "Timeline of the Founding of the University of Virginia." Edited and augmented by author additions. (Encyclopedia, Thomas Jefferson.)

mysteries, and questions in the narrative where narratees may project their own speculations. For example, Jefferson kept an aviary of mockingbirds and extensive journals on his scientific and agricultural explorations. Dropping a passing reference to his mockingbird aviary or a brief quote related to his agricultural passions humanizes Jefferson, and if a student shares that interest - a question is asked. If questions are responded to with a smile, and a suggested link to on-line archives of Jefferson's writings on the topic rather than specific answers students must research to scratch their curious itch and meet their design need. ${ }^{13}$ At these moments, scripting of imaginative narratives begins to transfer from instructor to students, and multiple participatory narratives emerge from the primary instructional narrative. Students begin to direct not only their own narrative but also the inquiry, research, story-world construction their narrative requires and design project that their narrative influences.

\section{CONCLUSIONS}

Narrative imagination is an effective means to understand and explore design, construction and inhabitation of place. As the preceding example illustrates, it is possible to imagine an instructional narrative that generates multiple design-narratives. It is also possible to use a narrative script to explore in detail the processes of design and successive inhabitation of place. Several lessons result from giving voice and form to the participatory and emergent narratives of architectural education and place.

First, the accuracy of imagination improves when narratives of construction and craft are accurately imagined. Accurate research provides the data that fuels accurate imagination. Also, a strong working knowledge of the processes and practices of different media, material and structural expressions improves trans-medial translation.

Second, inquiry into moments when the sources do not match leads to speculation on the reasons behind discrepancies. Deeper research prompted by inquiry leads to critical assessment of the strengths and weaknesses of each variation. The strategic gaps, small mysteries and invoked questions of the storyteller's art engage curiosity, encourage individual research in studio.

Third, imagining narratives of gender/race and social hierarchies in relation to contemporary and historic cultural settings help students develop empathy and understand the interplay between configuration of space and social-cultural habits as culture changes. While the narrative comparison in this paper is both trans-cultural and trans-historical, this observation also applies when trans-cultural or trans-geographic narrative comparisons occur within the same time period.

Fourth, trans-cultural and/or trans-historical study of place help students understand that social-cultural and physical order is rarely static, and even familiar places and uses embody traces of unfamiliar practices when engaged through alternate narratives.

Fifth, inhabitants actively reimagine, revise and re-configure places. In short, inhabitants are participants in scripting and enacting the narratives of place.

Lastly, formal design conventions often encode narrative practices of environmental comfort, social values and roles that can be visualized and scripted. For example, small rooms and aligned windows and doors of Jefferson's variant on Palladian order encode a cellular spatial configuration common to his era that can be enclosed for fireplace heating (or privacy) or opened up enfilade for summer ventilation. ${ }^{14}$ Sectional organization of service courts in the basements, classroom on the academic lawn, and private apartments with balconies above encode social, gender and racial realms that privileged the academic master and student. ${ }^{15}$ (Figure 5) Jefferson further emphasizes his personal values when he assigns the privileged location at the head of The Lawn to a library, The Rotunda. Filled with books that he himself selects, purchases and bequeaths to his university, this decision reflects the high value that Jefferson places on reason and knowledge.

In closing, narrative can aid imagination of temporal and physical patterns of individual, cultural and social actions, roles, customs and practices - and the configuration of space and material in response. 
It is hoped that in line with Jefferson's ambitions for his Academical Village, that critical practice of narrative imagination might develop the power and ambition of design students and practitioners to work fluidly across time to create, critique, and transform design practice, architectural place, and society.

\section{APPENDIX 1. EXAMPLES FROM THE SIX STUDIES ${ }^{16}$}

This series of six studies occurs during a 4-week required research project in a second-year design studio. A design assignment that offers students opportunities to apply their recently acquired narrative skills to design and presentation of a project that expresses their own contemporary design sensibility. While an example of using narrative to study a historic case is presented, narrative imagination is not limited to historic applications.

The examples that follow include both instructional prompts and student responses to the prompts for the six studies. Most examples are drawn from the work of a single student, Destiny Huff, to provide an example of one student's narrative imagination in several studies.

In the first iteration of the instructional narrative, ORDER was positioned as the 1st STUDY to create a digital model needed for performance studies. However, in later iterations of the course, the instructional narrative was changed to split construction of the 3D digital-model into stages aligned with the narrative for each study. This allowed the instructional narrative to develop a richer investigation of how formal configuration and order encode practices for phenomenal experience, comfort performance, and social order in both vernacular practice and Palladian order. The example illustrates this revision.

The revised instructional narrative begins with a simple PREPARATION study of geometric and proportional order used to develop a geometric scaffold on which the first 3D digital-model (performative narrative) is assembled. During the 2 nd through 5 th studies, students adjust the initial scaffold and synthesize new elements into the model as they learn more about construction techniques; environmental comfort, lighting, cooking technologies, and cultural use of space in 1817-25. Elements for each study are grouped as a

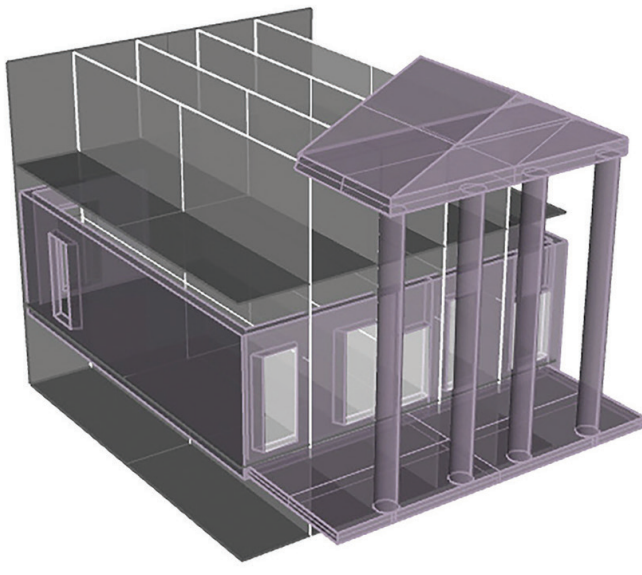

Figure 2a. Above is a single frame from a narrative video developed by Destiny Huff during Study.6 ORDER to illustrate the 8 step narrative of Palladian Grammar. This frame depicts Step 6. exterior ornamentation-addition of (porticos and) columns to the form, and the addition of first floor aperatures for Step 7. windows and doors; (apertures for breeze). separate layer set.

During Study.6 ORDER, students use their first digital model to create a second model (below left) to generate illustrations for a short animation that narrates their personal interpretation of an 8-step visual process for deriving the order, grammar and experience of their assigned pavilion. This narrative strongly influenced by the parametric shape-grammar develop by Mitchell G. Stiny in his 1978 article, The Palladian Grammar. ${ }^{17}$ The steps in this grammar narrative are as follows with modifications of Stiny's grammar by the instructor indicated in parentheses:

1. Grid definition (and geometry);

2. exterior-wall definition (thickness);

3. room layout;

4. interior-wall realignment;

5. principal entrances - porticoes and exterior-wall inflections;

6. exterior ornamentation-(porticoes and) columns;

7. windows and doors; (apertures for breeze);

8. termination (synthesis).

Figure $2 \mathrm{~b}$ illustrates a study of window and door alignments in Pavilion III used to both understand the principles of cross-ventilation (figure 4b) and to generate the 7th step of the parametric grammar, apertures for breeze (figure 2a). Figure 2a is a single frame from Destiny Huff's narrative video for the 8 steps of Palladian grammar. This frame illustrates the underlying geometric grid order (expressed as planes); the completed elements of Step.6 exterior ornamentation (porticoes and columns); and the first elements added during Step.7 (apertures-lawn level).

By the completion of the Study.6 ORDER, students have developed a narrative and learned a complete process for using sketches, cinematic digital model studies and other communication tools to imagine and visualize narrative embedded in designed place. In addition, the abstraction of order required to create the parametric shape-grammar narrative strips away the specificity of 19th century ornamentation to create a trans-historical bridge between present and past existences and order of a single place. This frees students to shift toward more contemporary language in the design investigations that follow.
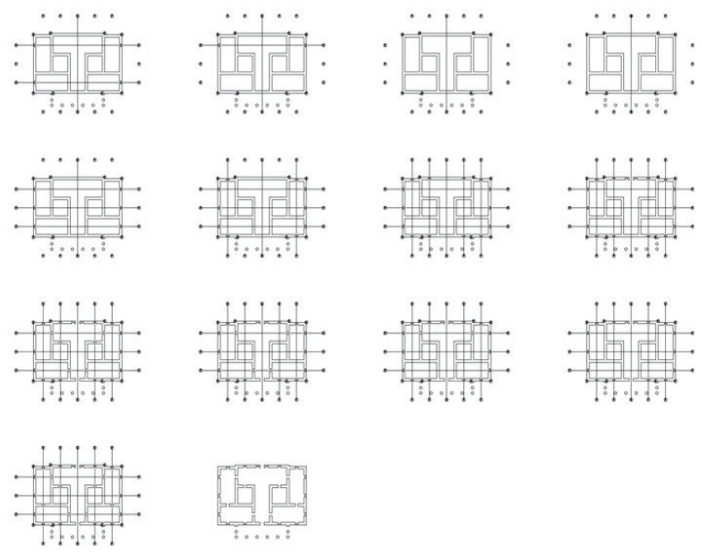

Figure $2 \mathbf{b}$. Above right is the Destiny Huff's plan study of aperture alignments for Step 7. windows and doors; (apertures for breeze). Figure $2 b$ at left shows the addition of these aperatures to the digital model. (source: Jefferson's Sketchbook, Collected Works from Architecture 272, edited by author, 2017) 


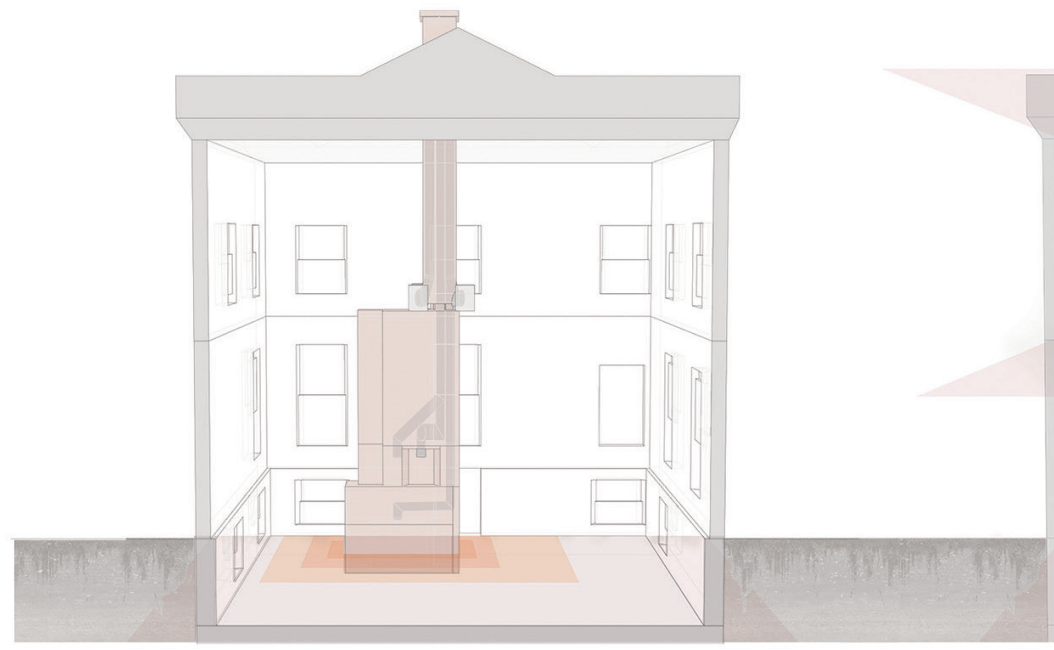

location of heath mass in relation to the space

The location of the hearth mass within this pavilion is slightly off-centered. Knowing the assembly and location of this form, one can begin to imagine its exterior shell as a thick lantern.

The effect of each fireplace and stove in combination with one another sends warmth throughout this space in a uniform way, ...the heat (rising) between levels (through open doors)

- Destiny Huff, observations 2017

Figure 3a. (above). Destiny Huff's graphic and written responses to the prompt for Study 3. Imagining Heat. (source: Jefferson's Sketchbook, Collected Works from Architecture 272, edited by author, 2017)

EXAMPLE: STUDY. 3 Imagining Heat.

In the lower left hand corner is an etching of fireplace and chimneys for the Decatur House, 1818, by Benjamin Henry Latrobe used as a visual prompt for narrative imagination of thermal performance and comfort. Destiny Huff's imagination of hearth-mass and flues (left) and the warmth and smoke in the pavilion III interior if the basement door is left open (right). During

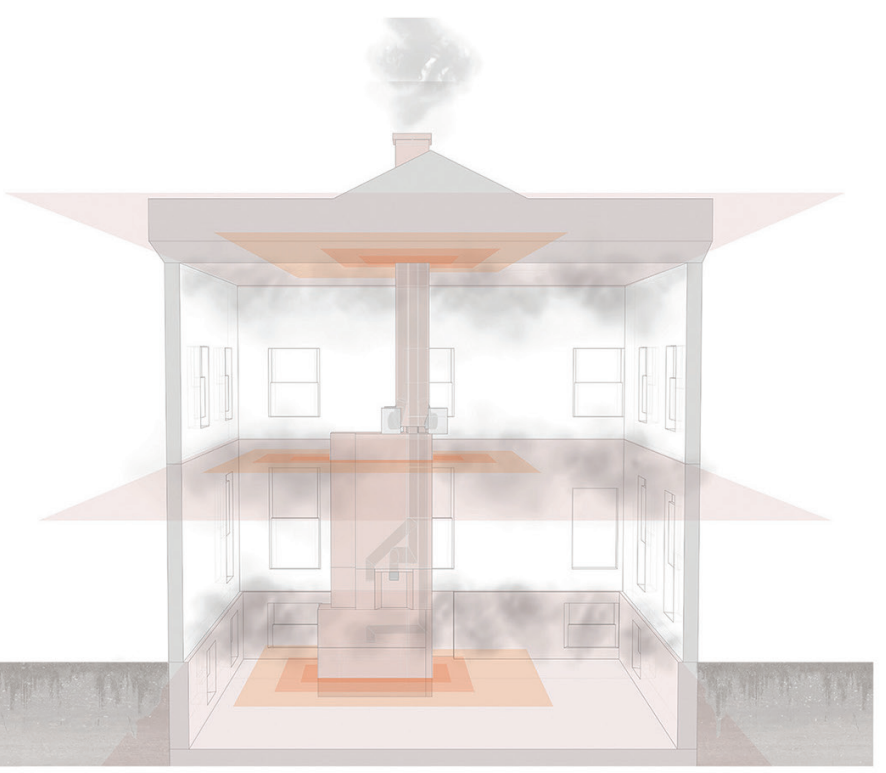

effect of thick lantern being lit by the hearth-lamp

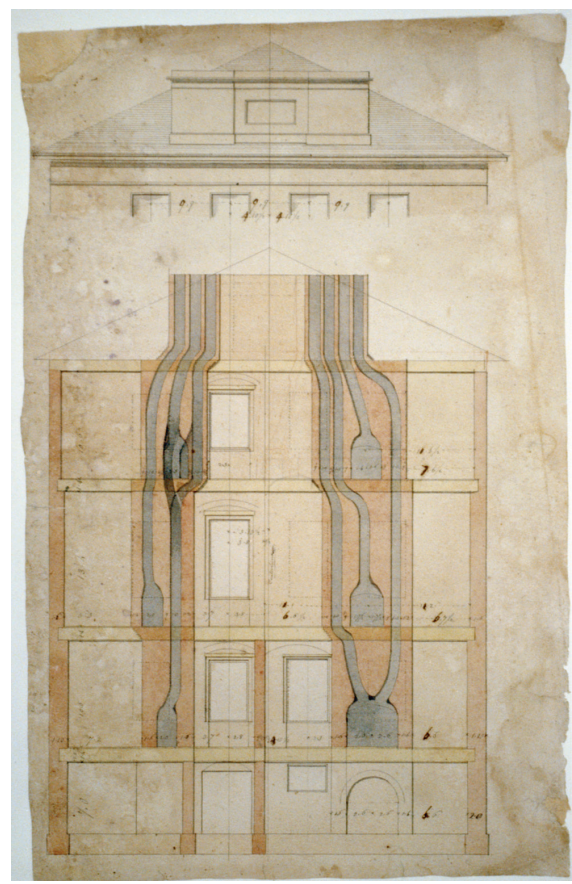

Figure 3b. The prompt for Study 3: House for Commodore Stephen Decatur, Benjamin Henry Latrobe, 1818. 1748 Jackson Place, N.W., Washington, D.C. Roof elevation, flue diagram, and parapet. drawing: ink, watercolor, and wash on paper. Collection of the Library of Congress.

Study. 3 Ms. Huff who had not studied chimneys or masonry construction before this exercise made many adjustments in chimneys, fireplaces, franklin stoves, and load bearing masonry walls as she better imagined thermal currents that guide the movement of smoke and the technology and craft of the mason. 

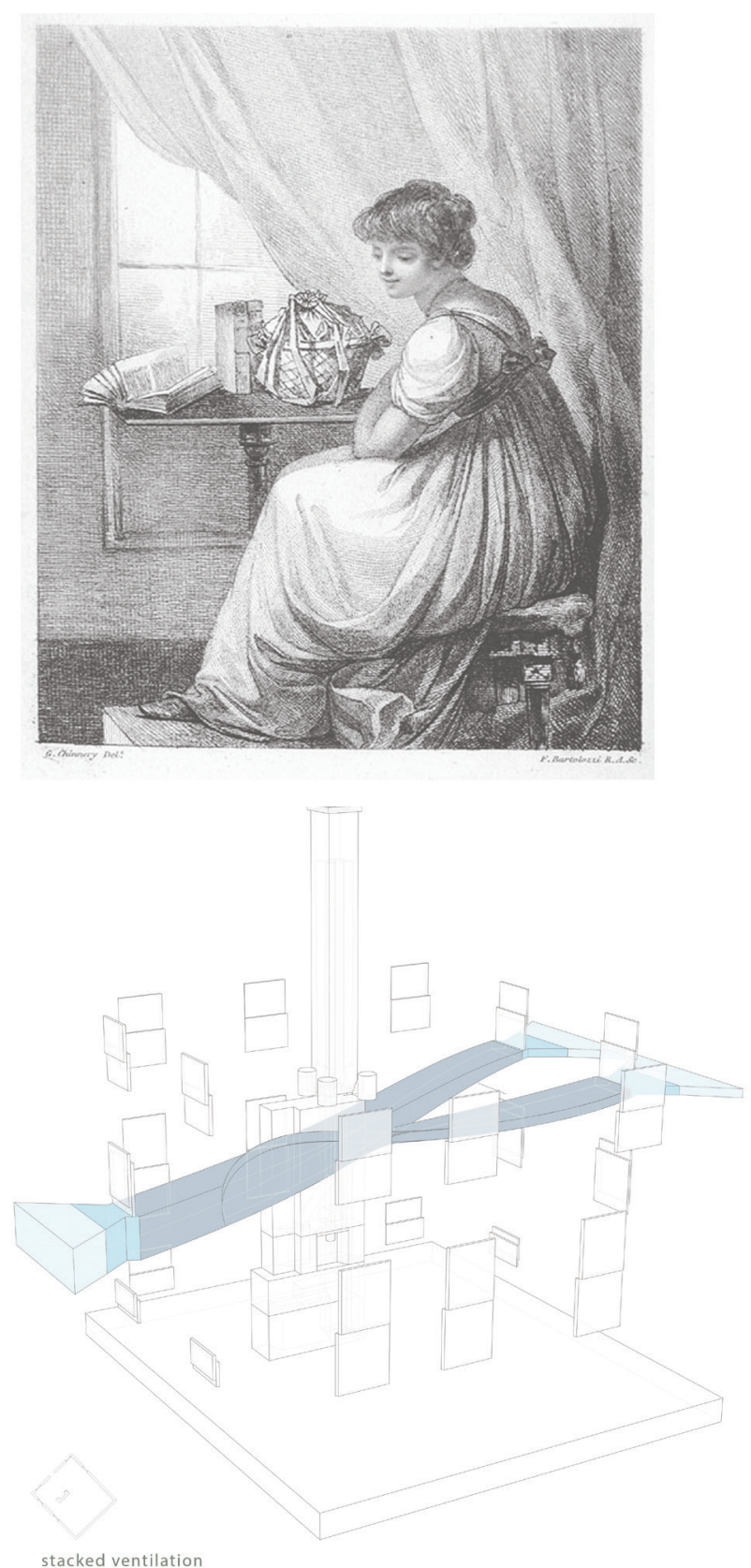

stacked ventilation

Figure 4a. (above). Visual Prompts for Study 4. Coolness of Breeze. Young Woman by a Window" by Franceso Bartolozzi, 1804, after George Chinnery. Above right is an illustration of double-sash window elements ( $p 19$, The Old House Journal, 1986).

EXAMPLES: STUDY. 4 Coolness of Breeze.

Above are images used to prompt students to imagine adjusting window sashes to ventilate a pavilion in the summer months. ${ }^{18}$ At left is an etching "Young Woman by a Window" by Franceso Bartolozzi, 1804, after George Chinnery. Above right is an illustration of double-sash window elements from ( $p 19$, The Old House Journal, 1986). Below is Destiny Huff's imagination of how different positions of the upper and lower window sashes might
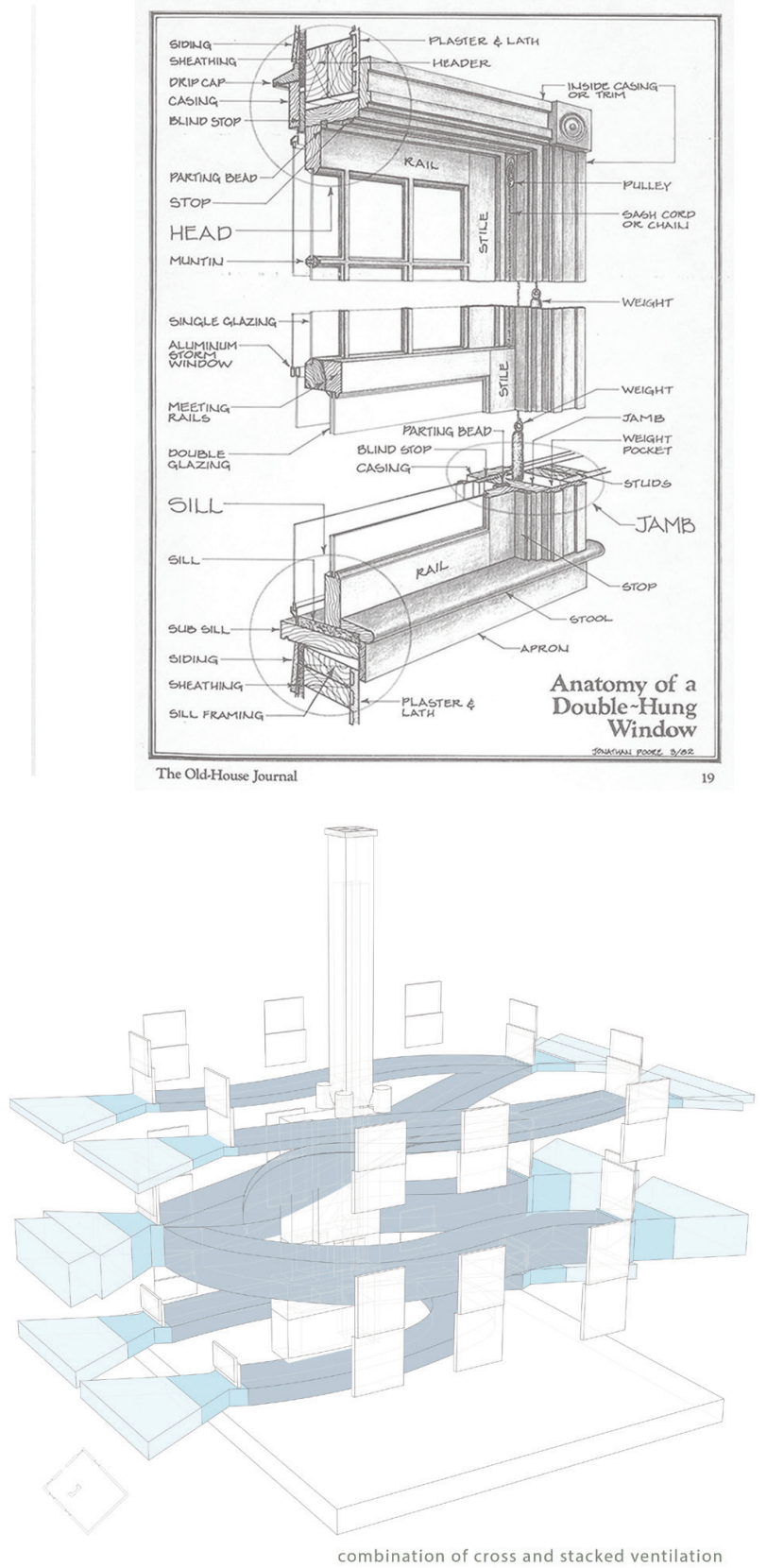

Figure 4b. (below) Examples of Destiny Huff's graphic and written responses to Study 4. Coolness of Breeze (source: Jefferson's Sketchbook, Collected Works from Architecture 272, edited by author, 2017)

affect the distribution and movement of a thermally motivated breeze between windows on the hot and cool facades of the Pavilion III. The hope is that students will transfer the practice of imaginative visualization developed in this course to help them visualize thermal flows during later coursework on passive ventilation principles and sizing of system elements. 


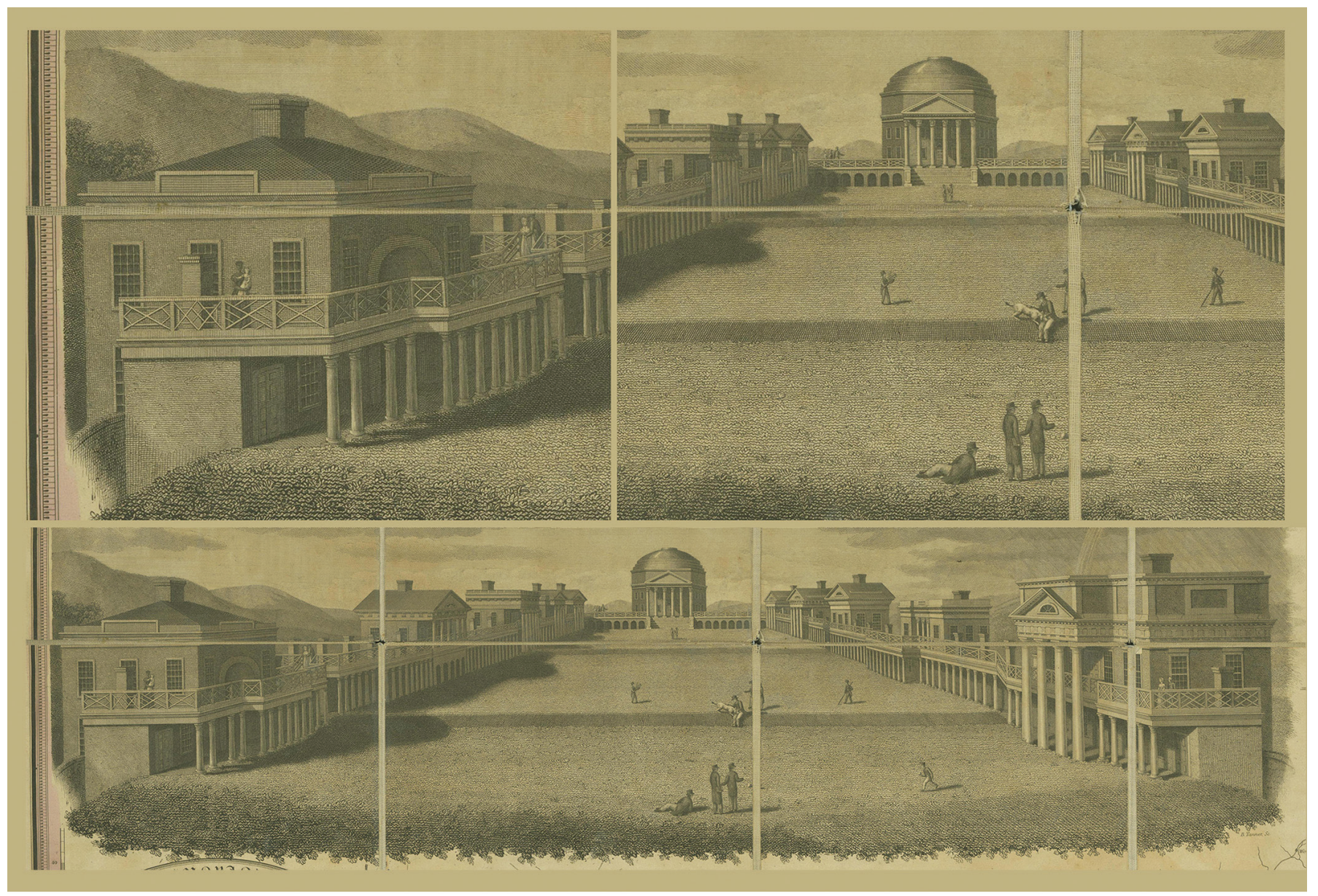

Figure 5a. Details from Benjamin Tanner's 1826 engraving of the Rotunda and the Lawn from Herman Boyë's 1826 map of Virginia, used to illustrate the prompt for Study 4.

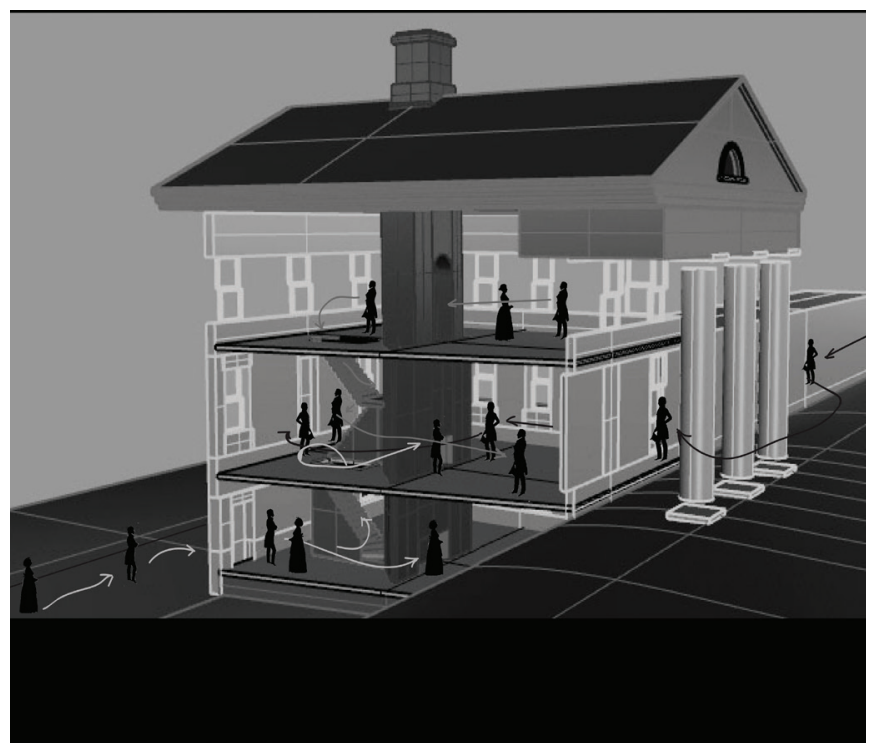

Figure 5b. Leah Cassetty and William Smith's response to the prompt for Study. 4 Occupants. (source: Jefferson's Sketchbook, Collected Works from Architecture 272, edited by author, 2017)

\section{EXAMPLES: STUDY. 4 OCCUPANTS}

Figure 5a. above is Benjamin Tanner's 1825 engraving of life on the Lawn, which is used to prompt students to imagine social conventions in 1817-1825. Note the depiction of gender realms and roles: young (male) scholars recline or converse on the lawn; women appear only on the apartment balconies- assisted by men or holding children. By 1922, only five female students had earned degrees at UVA and gender remained a consideration for admission to UVA until 1972. It wasn't until 1950 that Gregory H. Swanson the first African American was admitted to UVA in 1950 following a lawsuit.

Figure 5b. at left shows Leah Cassetty and William Smith's response to the prompt to visualize 19th century social territories and hierarchies for Pavilion IV. The master has free access to all levels of the pavilion, lawn and service areas. The master's wife and children are limited to the domestic territories of upstairs apartment, balcony and the back garden (not shown). Servant/ slaves occupy the basement rooms, service yard and back alley, which they would leave only when summoned to serve upstairs. Students, who are all men in 1825 live in small rooms on the lawn level and attend classes and dinners with the master on the lawn level of the pavilions. ${ }^{19}$ 


\section{Acknowledgments}

Thanks to Destiny Huff and the team of Leah Cassetty and William Smith whose studies of Pavilion III and Pavilion IV respectively are used to illustrate this article. Thanks also to all members of the 2017 , 2015, 2015 Jefferson's Sketchbook courses whose comments questions and insights affected my instructional narratives and the preparation of this article:

Members of the Jefferson's Sketchbook studio in 2017 include: Leah Cassetty, Sarah Hime, Jessica Howard, Destiny Huff, John Huddleston, Andrew Owens, Tyler Sanford, Michael Swartz, William Smith and Victoria Eslick.

Members of the Jefferson's Sketchbook studio in 2017 include: Kim Ballard, Anna Katherine Biggs, Summer Earnest, Joseph Ellis, Meredith Graves, Emily Lange, Destin Manous, Kendall Maples, Alyssa McAlister, Casey Myers, Dalton Oatman, Alec Persch, Esteben Pilo-Pias, Zane Russell, David Aaron Wright.

Members of the original Jefferson's Sketchbook studio in 2014: Cody M. Bancroft, Haven Bush, Nicki Coward, Jennifer Elder, William Harvell, Joseph Kutz, Macy McCarty, Spencer McCarty, Brittany Peters, Jonathan Ruiz, Emilee Wilson, Austin Winter.

\section{Endnotes}

1. Ryan, Marie-Laure. p4, "Narrative and the Split Condition of Digital Textuality." Dichtung Digital 5, no. 1 (April 2005). Accessed 7/6/17, 12:24 PM at http://www.dichtung-digital. de/2005/1/Ryan/

2. Works that contribute to the author's framing of imaginative narrative in this discussion include: Barthes, Roland. ImageMusic-Text. Translated by S. Heath. London: Harper Collins, 1977. (Includes 'Death of the Author' and 'From Work to Text'.) Duisit, Roland Barthes and Lionel. 1975. "An Introduction to the Structural Analysis of Narrative." New Literary History 6 [2, On Narrative and Narratives (Winter, 1975)]:237-272. Genette, Gerard. 1980. Narrative Discourse. Translated by Lewin. Ithaca: Cornell University Press. Jenkins, Henry. "Confronting the Challenges of Participatory Culture: Media Education for the 21st Century (Part Two)." In Confessions of an ACA-Fan, edited by Henry Jenkins: Jenkins, Henry, 2006. Jenkins, Henry "Transmedia Storytelling 101." In Confessions of an ACA-Fan, edited by Henry Jenkins: Jenkins, Henry, 2007. Jenkins, Henry Convergence Culture: Where Old and New Media Collide. Revised edition ed. New York: NYU Press, 2008. Jenkins, Henry "Transmedia 202: Further Reflections." In Confessions of an ACA-Fan, edited by Henry Jenkins: Jenkins, Henry, 2011. Phelan, James, and Peter J. Rabinowitz. 1994. "Understanding Narrative." In Understanding Narrative, 1-15. Columbus: Ohio State University Press. Ryan, Marie-Laure 2007. "Beyond Ludus: narrative, videogames and the split condition of digital textuality." In Videogame, Player, Text, 8-28. Manchester University Press. Thomas, Bronwen 2016 Narrative, The Basics. 1st ed. Oxford, New York City: Routledge.Fiske, John. 1990. Introduction to Communication Studies. 2nd ed. London: Routledge.Fludernik, Monika. 1996. Towards a 'Natural' Narratology. London: Routledge.Levi-Strauss, Claude. 1955. The Structural Study of Myth. The Journal of American Folklore, 68/270,428-44. LeviStrauss, Claude. 1966. The Savage Mind, The Nature of Human Society Series. Chicago: The University of Chicago Press.

3. Barthes, Roland. Image-Music-Text. Translated by S. Heath. London: Harper Collins, 1977. (Includes 'Death of the Author' and 'From Work to Text'.) From p147 in 'Death of the Author' "Succeeding the Author, the scriptor no longer bears within him passions, humours, feelings, impressions, but rather this immense dictionary from which be draws a writing that can know no halt: life never does more than imitate the book and the book itself is only a tissue of signs, an imitation that is lost, infinitely deferred. .. In the multiplicity of writing, everything is to be disentangled, nothing deciphered; the structure can be followed, 'run' (like the thread of a stocking) at every point and at every level, but there is nothing beneath: the space of writing is to be ranged over, not pierced; writing ceaselessly posits meaning ceaselessly to evaporate it, carrying out a systematic exemption of meaning." Note: While Barthes' convention of the scriptor is adopted, this paper focuses primarily on the processes of narrative construction and delivery rather than on the subsequent processes by which narratees receive meaning. Thus, disciplinary discussions of modern and post-modern meaning and signification theory that relate to later stages of narrative process are minimized.

4. (Gennette, 2005. Thomas, 2016.)

5. Thomas, Bronwen. "Chapter 2, Narrative Structures." and "Chapter 3, Narrative Voice and Point of View." In Narrative, the Basics, 43-61. Oxford, New York City: Routledge, 2016.

6. Delany, Samuel. Dhalgren Bantam, 1974. 1st Vintage Books ed edition (May 15, 2001). Pynchon, Thomas. Gravity's Rainbow. 1973. Vonnegut, Kurt. Slaughterhouse Five. Delta, 1969

7. Tennessee, University of. 2016-2017. "Catalog description for the course: ARCH 272 - Architectural Design II: Place." In Undergraduate Catalog University of Tennessee 2016-2017 online. Knoxville, TN: University of Tennessee. "Contextual determinants in architectural design. Role of the landscape in architectural design. Methods of analyzing place and precedents in determining design strategies. The role of function, habitation, movement, structure and scale. Development of design processes, including analytical skills, diagramming, and organizational strategies. Representational skills developed including drawing, diagramming, modeling techniques, and use of computer aided visualization techniques." Prereq: 221, 271

8. Jefferson, Thomas. "Thomas Jefferson to the Trustees of the Lottery for East Tennessee College, 6 May 1810." Founders Online, National Archives, accessed April 11, 2019, Permalink: http://founders.archives.gov/documents/ Jefferson/03-02-02-0322 [Original source: The Papers of Thomas Jefferson, Vol. 2, 16 November 1809 to 11 August 1810, edited by J. Jefferson Looney, pp. 365-66. Princeton: Princeton University Press, 2005.] From Jefferson's letter "To the Trustees of the Lottery for East Tennessee College": "I consider the common plan, followed in this country, but not in others, of making one large \& expensive building as unfortunately erroneous. it is infinitely better to erect a small and separate lodge for each separate professorship, with only a hall below for his class, and two chambers above for himself; joining these lodges by barracks for a certain portion of the students opening into a covered way to give a dry communication between all the schools. the whole of these arranged around an open square of grass \& trees would make it, what it should be in fact, an academical village, instead of a large \& common den of noise, of filth, \& of fetid air. it would afford that quiet retirement so friendly to study, and lessen the dangers of fire, infection \& tumult. every professor would be the police officer of the students adjacent to his own lodge, which should include those of his own class of preference, and might be at the head of their table if, as I suppose, it can be reconciled with the necessary economy to dine them in smaller \& separate parties rather than in a large \& common mess. these separate buildings too might be erected successively \& occasionally, as the number of professorships \& students should be increased, or the funds become competent..."

9. Figure 1. in this paper provides a typical example of Jefferson's sketches for the Pavilions. "No. 1. Pavilion West." University of Virginia, Thomas Jefferson, undated. (circa 1818). (http:// www2.iath.virginia.edu/wilson/drawings/images/large/N355. jpg access date 2/2/2017). Students were asked to accurately scale digital scans of Jefferson's sketches (10 grid spaces $=1$ ") and print the sketches in color at full scale (1:1)-preferably on vellum, to use during their analyses for the six studies. The same policy was followed with maps and other archive documents used in the classroom. The goal was to create a temporally doubled experience of documents, as Jefferson would have held and worked with them in 1817-1824, and as a contemporary digital artifact. 
10. McLaughlin, Jack. c1988. Jefferson and Monticello: the biography of a builder. 1st ed. New York: Henry Holt and Company.

11. Encyclopedia, Thomas Jefferson. "Timeline of the Founding of the University of Virginia." https://www.monticello.org/site/ research-and-collections/timeline-founding-university-virginia. The Timeline of Key Events in Table 2 used during studio research is primarily based on "Timeline of the Founding of the University of Virginia." Encyclopedia, Thomas Jefferson. Additional dates are added to the timeline as students read Jefferson's accounts of his adventures, interests and encounters with the modern technologies of the day in his voluminous archive of letters and other writings.

12. An example of a technical teaser: Jefferson writing about his encounter with the Armand lamp in a letter to James Madison. "There is a new lamp invented here lately which with a very small consumption of oil (of olives) is thought to give a light equal to six or eight candles. The wick is hollow in the middle in the form of a hollow cylinder, and permits the air to pass up thro' it. It requires no snuffing. They make shade candlesticks of them at two guineas price, which are excellent for reading and are much used by studious men." From: Jefferson, Thomas. "From Thomas Jefferson to James Madison, 11 November 1784." In The Papers of Thomas Jefferson, Vol. 7, 2 March 1784 - 25 February 1785, edited by Julian P. Boyd, 503-08. Princeton: Princeton University Press, 1953.

13. Encyclopedia, Thomas Jefferson. "Mockingbirds" https://www. monticello.org/site/research-and-collections/mockingbirds and "Agriculutre and Garden" https://www.monticello.org/site/ research-and-collections/tje/agriculture-and-gardening. The Thomas Jefferson Encyclopedia is a research and education web-site supported by the Thomas Jefferson Foundation. Well organized hyper-linked endnotes on this archival website facilitate easy access to a range of primary source documents available on-line encouraging students to broadly explore Jefferson and the culture of 19th century Virginia.

14. Evans, Robin. 1997. "Figures, Doors and Passages." In Translations from Drawing to Building and Other Essays, 54-91. Cambridge, MA.: The MIT Press. Evans essay is used to raise awareness of the relationship between social status, privacy and class distinction in the arrangement and use of space. Discussion then departs into a broader discussion that links social themes Evans addresses to climatic performance aspects of the compartment and enfilade in the Jeffersonian pavilion as well as the difference between Continential and Colonial social structures.

15. Refer again to the text of the letter in note 9. Jefferson, Thomas. "Thomas Jefferson to the Trustees of the Lottery for East Tennessee College, 6 May 1810." Founders Online, National Archives, accessed April 11, 2019, Permalink: http://founders. archives.gov/documents/Jefferson/03-02-02-0322 [Original source: The Papers of Thomas Jefferson, Vol. 2, 16 November 1809 to 11 August 1810, edited by J. Jefferson Looney, pp. 36566. Princeton: Princeton University Press, 2005.

16. All examples of student work used to illustrate this paper are from Jefferson's Sketchbook, Collected Works from Architecture 272, edited by Tracy Walker Moir-McClean. Knoxville,TN: University of Tennessee at Knoxville, 2017 (unpublished).

17. Stiny G, Mitchell WJ 1978. "The Palladian grammar." Environment and Planning B 5:pp. 5-18.

18. In the verbal narrative that accompanies these images an instructor encourages students to imagine a small woman in a corseted dress struggling to adjust the lower sash of a doublesash in the master's apartment as it starts to rain (image 2). Then, to wonder why the carpenter designed and constructed a complicated heavy window where both upper and lower sashes move? Why does the top sash overlaps the bottom to the exterior? Why is each sash is attached to ropes and counterweights concealed behind mouldings? Connected by a narrative, each element of the window design begins to make sense. If the woman is hot, she is able to adjust upper and lower mobile sashes independently to arrange thermal air ows across the room. If the upper sash overlaps the lower sash to cover the gap between sashes, rain cannot enter that gap and drip on her dress or the table as she adjusts the window. Pulleys and counter-weights help the small woman to lift and lower the heavy sash easily. Finally, when the rope frays or falls off the pulley, a carpenter can pry off the molding and replace the rope. This example illustrates the difference between memorizing a correct con guration of lines to be drawn to represent a double-sash window and using narrative to understand the design of a double-sash window.

19. Mclnnis, Maurie D. Daacke, Kirt von. Nelson,Louis P. Ford, Benjamin. Zehmer, James. Sewell, Jessica E. Johnston, Andrew. Educated in Tyranny: Slavery at Thomas Jefferson's University. University of Virginia Press 2019. 